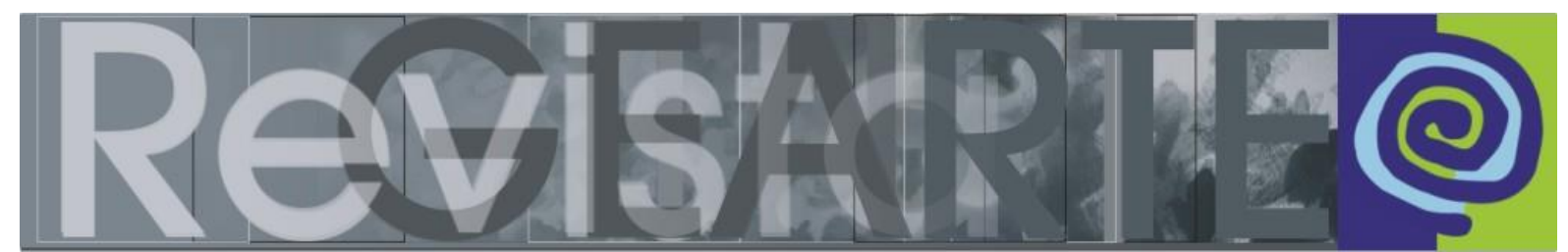

ISSN 2357-9854 | e-ISSN 2596-3198 (online)

\title{
\#OfuturoÉfake?Kkkkk O tempo passa e a queda é sempre no mesmo buraco?
}

\author{
Fernanda Pereira da Cunha \\ (Universidade Federal de Goiás - - UFG, Goiânia/GO, Brasil)
}

\begin{abstract}
RESUMO - \#OfuturoÉfake?Kkkkk O tempo passa e a queda é sempre no mesmo buraco? - Análise de aspectos históricos brasileiros, que colocam à baila os ecos de nossa herança colonialista, cujo legado se apresenta como elemento fundamental na (de)formação da identidade e por conseguinte na capacidade da expressão estético-digital na contemporaneidade, no tocante ao (des)comprometimento com o desenvolvimento da consciência crítica em prol da autogovernança. A década de 1990 no Brasil marca a transição da mente analógica para a mente digital, cujo processo de transição está imbrincado na tessitura com nossa herança colonialista, que se vincula com os processos tecnológicos de produção e "culturalização" no tocante à espetacularização e exploração humana. O objetivo central é refletir acerca de respostas e/ou questões que se apresentam na cartografia do ontem, do hoje sobre a estética digital que se assevera rumo ao amanhã.
\end{abstract}

PALAVRAS-CHAVE

Ciberarte/Educação. (Des)colonização midiática. Massificação. Mente analógica. Mente digital.

RESUMEN - \#¿Esfalsoelfuturo?Kkkkk ¿El tiempo pasa y la caída siempre está en el mismo hoyo? - Análisis de los aspectos históricos brasileños, que sacan a la luz los ecos de nuestra herencia colonialista, cuyo legado se presenta como un elemento fundamental en la (des) formación de identidad y, por lo tanto, en la capacidad de expresión estética-digital en los tiempos contemporáneos, con respecto a ( dis) compromiso con el desarrollo de una conciencia crítica a favor del autogobierno. La década de 1990 en Brasil marca la transición de la mente analógica a la mente digital, cuyo proceso de transición está entrelazado en el tejido con nuestra herencia colonialista, que está vinculada a los procesos tecnológicos de producción y "culturalización" con respecto a la espectacularización y la exploración humana. El objetivo principal es reflexionar sobre las respuestas y / o preguntas presentadas en la cartografía de ayer, del hoy sobre la estética digital que se afirma hacia el mañana.

PALABRAS CLAVE

Cyberart / Educación. Media (des) colonización. Masificación. Mente analógica. Mente digital.

\begin{abstract}
Kkkkk Time passes and the fall is always in the same hole? - Analysis of Brazilian historical aspects, which bring to light the echoes of our colonialist heritage, whose heritage is presented as a fundamental element in the (de)formation of identity and, consequently, in the capacity of aesthetic-digital expression in contemporary times, with regard to (de) commitment to the development of critical awareness for self-governance. The 1990s in Brazil marks the transition from the analogical to the digital mind, whose transition process is intertwined in the fabric with our colonialist heritage, which is linked to the technological processes of production and "culturalization" regarding spectacularization and human exploitation. The main objective is to reflect on the answers and/or questions that are presented in the cartography of yesterday, today about the digital aesthetic that asserts itself towards tomorrow.
\end{abstract}

KEYWORDS

Cyberart/Education. Media (de)colonization. Massification. Analog mind. Digital mind.

CUNHA, Fernanda Pereira da. \#OfuturoÉfake?Kkkkk O tempo passa e a queda é sempre no mesmo buraco? 133

Revista GEARTE, Porto Alegre, v. 7, n. 1, p. 133-154, jan./abr. 2020.

http://dx.doi.org/10.22456/2357-9854.99783 


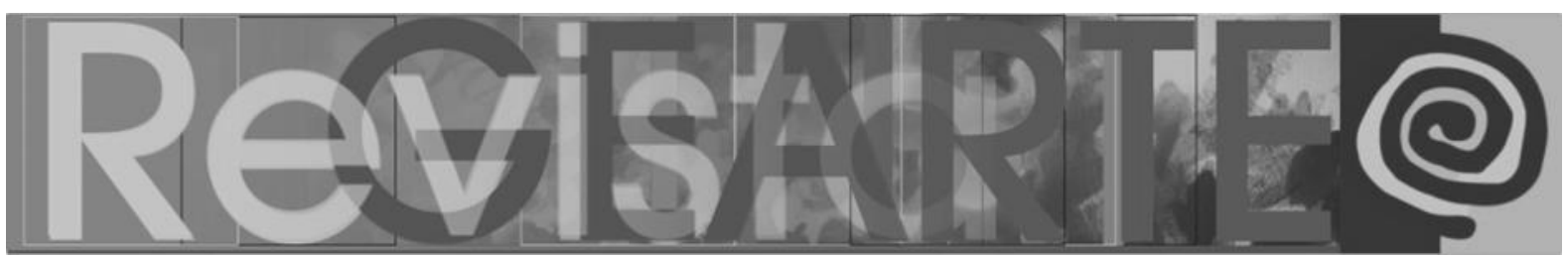

Autopsicografia

"O poeta é um fingidor Finge tão completamente Que chega a fingir que é dor A dor que deveras sente. $E$ os que lêem o que escreve, Na dor lida sentem bem, Não as duas que ele teve, Mas só a que eles não têm. E assim nas calhas de roda

Gira, a entreter a razão,

Esse comboio de corda Que se chama coração." (Fernando Pessoa, 1932)

Conte-me, caro leitor, qual a qualidade estética do comboio de corda de seu coração? Êta coração que bate! Bate em qual tempo de real ficção?

Em sua gênese histórica, autopsicografada, a experiência digital do futuro inevitavelmente inserir-se-á pelas marcas cartografadas do passado e demarcadas pelas ações no presente, cujo presente, que ilumina os vestígios do passado, conduz este ensaio a especial atenção analítico-crítica sobre a aguda uniformização estética que se acentua no cenário das expressões de nossos jovens da era digital.

$E$, se pela ciência também se advém probabilidades, podendo as probabilidades serem rastreadas pelos vestígios históricos das trilhas produzidas pelas ações humanas com base em proporcionar maior subsídio à vida do amanhã: O tempo do ontem e do agora levam para qual estatística futurística no tocante ao desenvolvimento da consciência crítica balizada pela qualidade estética da expressão autogovernativa da sociedade em rede?

A professora Ana Mae Barbosa costuma dizer: "olho para trás para compreender o agora". Rezende e Ferraz observam que este olhar:

Pode auxiliar o professor a entender as raízes de suas ações, bem como o seu próprio processo de formação. Ao mesmo tempo, contribui para que se tenha consciência de que ainda permanecem ignoradas muitas questões referentes ao papel específico da educação escolar e, também 


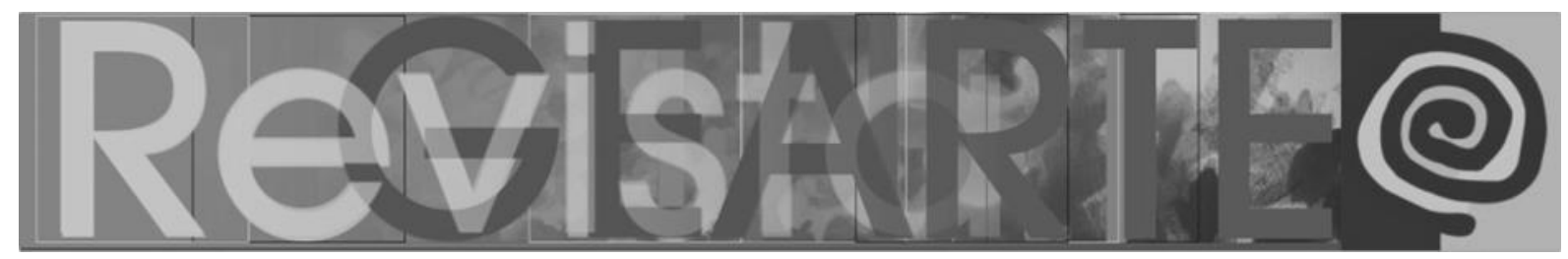

das aulas de Arte, na mudança e melhoria das relações sociais. (REZENDE; FERRAZ, 1992, p. 39).

Assim, vale salientar especial estranheza a pouca percepção conceitual acerca da grande importância atribuída ao futuro em relação ao passado pelas trilhas do presente. Como adverte o educador Paulo Freire, o que difere o homem dos outros animais é a sua historicidade, pois, em vez de estar num mundo natural como as demais espécies, o homem se insere num mundo cultural,

[...] herdando a experiência adquirida, criando e recriando, integrando-se às condições de seu contexto, respondendo a seus desafios, objetivandose a si próprio, discernindo, transcendendo, lança-se o homem num domínio que lhe é exclusivo - o da História e o da Cultura. (FREIRE, 2001, p. 9).

Deste modo, não consigo desassociar aspectos culturais e seus contextos históricos sem considerar a relevância da interconexão entre o ontem e o hoje, conexão esta que pode nos lançar mais crítica e conscientemente adiante.

Dada a cibercartografia humana que vem se potencializando de modo cada vez mais fluido nos últimos 30 anos, com alto expoente nas expressões massivas, cujas expressões vêm se ritualizando de modo cada vez mais viral nas mídias sociais, traz a importância à necessidade de se analisar com atenção historiográfica cuidadosa sobre aspectos da uniformização da estética expressiva em suas manifestações dialógicas.

\section{Vestígios históricos e contextuais da uniformização dos sentidos}

Neste recorte, na década dos anos de 1990 o filósofo e sociólogo francês Pierre Lévy $(1993,1996,1999)$, pesquisa sobre ciência da informação com foco acerca do impacto da internet nas humanidades digitais, traz à baila o conhecimento por simulação como forma de expressão digital, que advém da culminância migratória da sociedade oriunda da era analógica para a digital.

A exemplo deste processo migratório da expressão do analógico para o digital, em que se pode conferir, por exemplo, a transposição da "máquina de 


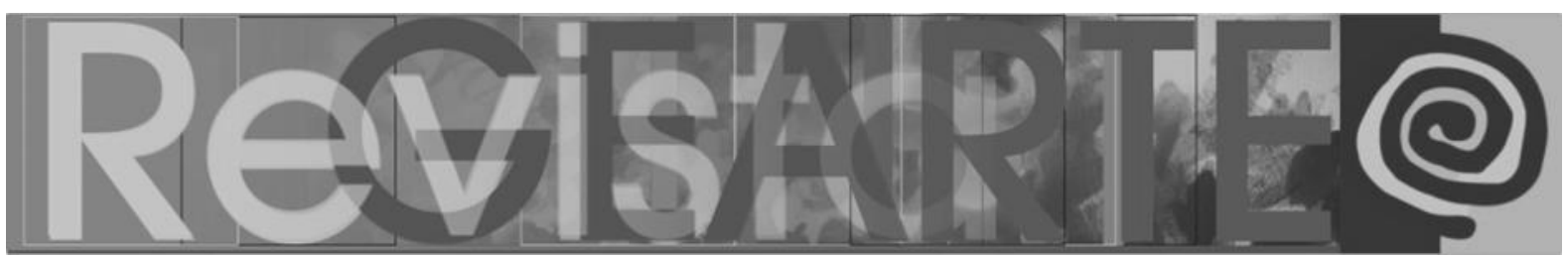

escrever" por programas computacionais na expressão escrita, caracteriza-se a busca da garantia da performance digital através da simulação para o conhecimento digital subsidiado pelo domínio da mente analógica. Este período de transição da mente analógica para a digital é fato histórico significativo pelos auspícios advindos da nova forma de expressão bem como ascensão da cognição perceptiva digital que viria a mudar a comunicação da humanidade. Da humanidade digital.

Entretanto, aos que resistiam a transformação tachavam Pierre Lévy e outros pesquisadores, que prediziam a enunciação que já se aflorava, de românticos da cibercultura. A resistência, característica marcante da tecnofobia computacional que se alastrou em boa porção da geração analógica, negava esta nova prática digital que se disseminava de modo potente e irreversível, através de discursos minimizadores e de certo ofensivos aos que aderiam a era digital.

Assim, os novos processos cognitivos que se manifestavam na transição do analógico para o digital foram negligenciados, em sua grande maioria no Brasil, postos à margem como algo menor à mercê do tecnicismo para formar exclusivamente mão de obra digital a serviço de uma elite "criadora" - "intelectual", dominante - colonizadora. Este hiato, tão potente no Brasil, que na transição da mente analógica para a digital chegava a ser chique não saber operar um computador, um terminal de banco.

É lamentável como a burguesia brasileira repete com maestria histórica seus preconceitos sectários. Relembremos, por exemplo, pela nossa herança do sistema educacional jesuítico, o preconceito sobre o trabalho manual que era coisa de escravo, assim artes plásticas pela sua natureza ao ofício manual carrega no Brasil uma arte menor em relação às outras manifestações artísticas, como explica a professora Ana Mae Barbosa:

Refletindo a influência da educação jesuítica, a qual moldou o espírito nacional, colocava no ápice de sua escala de valores as atividades de ordem literária, demonstrando acentuado preconceito contra as 


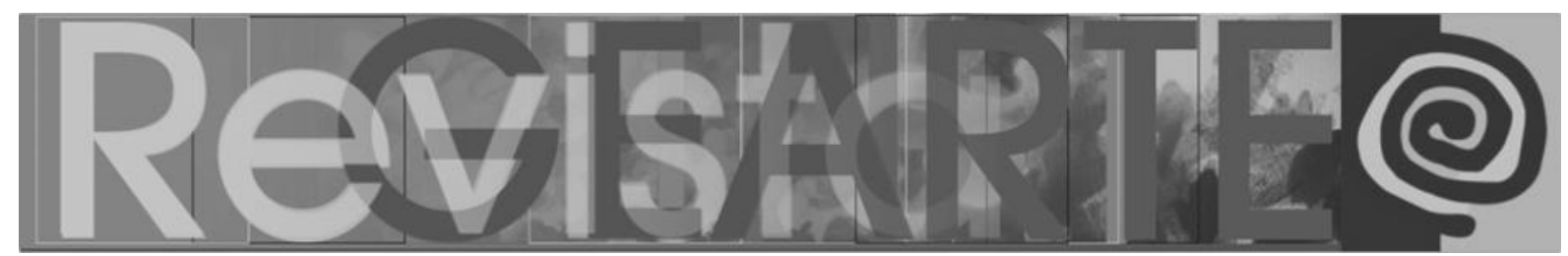

atividades manuais, com as quais as Artes Plásticas se identificavam pela natureza de seus instrumentos.

Este fora o modelo implantado pelos jesuítas, a cargo dos quais estivera a educação brasileira desde a época do descobrimento até 1759, quando foram expulsos do Brasil por razões político-administrativas.

Embora ausentes das atividades educativas, eram os ecos de suas concepções que orientavam nossa cultura quando aqui chegou D. João VI, e oito anos depois quando chegou a Missão Francesa, mesmo havendo quem afirme que suas influências ainda ressoam entre nós.

E conclui:

Isto se deveu ao fato de que nenhum sistema de ensino fora estruturado para substituir a bem organizada rede escolar jesuítica.

Expulsá-los não significou, portanto, expurgar o país de suas idéias, que continuaram a germinar em virtude da ausência de idéias novas que substituíssem aquelas vinculadas pela ação missionária e colonizadora no Brasil. (BARBOSA, 1999, pp. 21-22)

Neste viés, as atividades manuais foram rejeitadas por serem consideradas próprias "dos trabalhos de escravos que, vindos da África, foram explorados no Brasil durante três séculos." (BARBOSA, 1999, p. 22). Desta maneira, as escolas dos homens livres recusavam este tipo de atividade.

Note-se, pois, a transposição preconceituosa do labor manual que se é atribuído ao computador, excluindo completamente a produção inventiva que se pode exercer através dos meios digitais. Neste paradigma, o computador é coisa de operário, computador como máquina operacional e não equipamento que pode viabilizar processos da elaboração humana... A apropriação do contexto a serviço do sectarismo... A máquina de escrever sob manipulação contextual da condição de ser rico ou pobre - de acordo com a imposição de cena, devendo circunscrever a estética daquela vida: se escritor ou auxiliar de escritório...

A ditadura colonizadora do status quo impõe o locus social vinculando-o ao seu valor capital: do privilegiado ao marginalizado. A colonização da alma, em seus valores intrínsecos à servidão, estabelece a estagnação sociocultural, demarcando castas e garantindo o seu poder autoproclamado pelo acúmulo de capital tendo, por conseguinte, uma sociedade controlada pela imposição do capital cultural. Assim que as conjunturas do capitalismo servil estão intrinsecamente ligadas às 


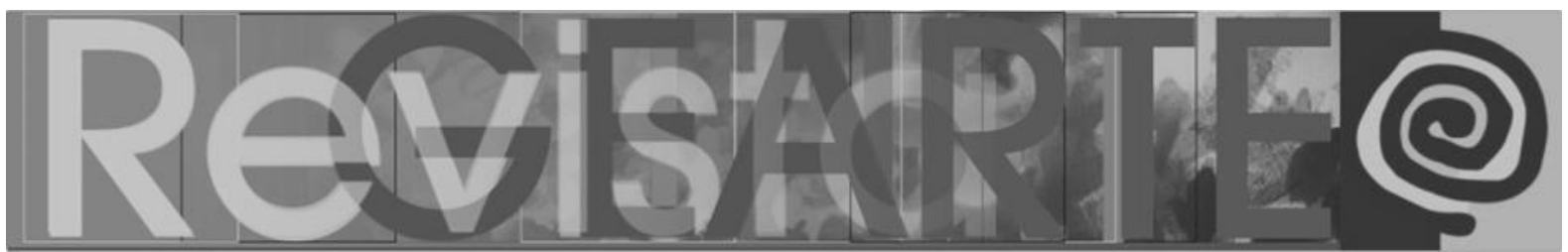

relações tecnológicas da exploração humana, pois o sistema capitalista tem como objetivo primordial "o aumento da produtividade, que é o eixo fundamental do processo de exploração" (BERNARDO, 1998, p. 127). Para Karl Marx a "acumulação do capital é, portanto, multiplicação do proletariado" (MARX, 1984, p. 188). Como explicava Bernard de Mandeville no começo do século XVIII:

Onde a propriedade esteja suficientemente protegida, seria mais fácil viver sem dinheiro do que sem pobres, pois quem faria o trabalho? (...) Assim como os trabalhadores devem ser preservados de morrer de fome, também não deveriam receber nada que valha a pena ser poupado. Se aqui e ali alguém da classe mais baixa, por incomum esforço e apertando o cinto, eleva-se acima das condições em que foi criado, ninguém deve impedi-lo; sim, é inegavelmente o plano mais sábio para cada pessoa na sociedade, para cada família, ser frugal; mas é do interesse de todas as nações ricas que a maior parte dos pobres nunca esteja inativa e, ainda assim, continuamente gaste o que ganha (MANDEVILLE apud MARX, 1984, p. 189).

Neste aspecto, concebe-se a pessoa como instrumento-vivo passível de reconfigurações para servir tanto como força-tarefa - instrumento de produção como para consumir a produção por esta força-tarefa gerada - instrumento de consumo -, pois o empregado devolve ao capitalista o que ganha trabalhando com o que consome.

Bernard de Mandeville assim descreve as concepções dos capitalistas sobre o assalariado no começo do século XVIII:

Aqueles que ganham a vida com seu labor diário (...) não têm nada que os aguilhoe para serem serviçais, senão suas necessidades, que é prudente aliviar, mas loucura curar. A única coisa que pode tornar o homem trabalhador esforçado é um salário moderado. Um pequeno demais torna-o, conforme seu temperamento, desalentado ou desesperado; um grande demais torna-o insolente e preguiçoso (...). Do desenvolvimento até aqui segue que, numa nação livre, em que não sejam permitidos escravos, a riqueza mais segura consiste numa porção de pobres laboriosos. Além de serem a inesgotável fonte fornecedora da marinha e do exército, não poderia haver sem eles satisfação, e nenhum produto de qualquer país seria valorizável. Para fazer uma sociedade [que, obviamente, consiste em não-trabalhadores] feliz e o povo contente, mesmo nas piores circunstâncias, é necessário que a grande maioria permaneça tanto ignorante quanto pobre. O acontecimento amplia e multiplica nossos desejos, e quanto menos um homem deseja, tanto mais facilmente suas necessidades podem ser atendidas (MANDEVILLE apud MARX, 1984, p. 189). 


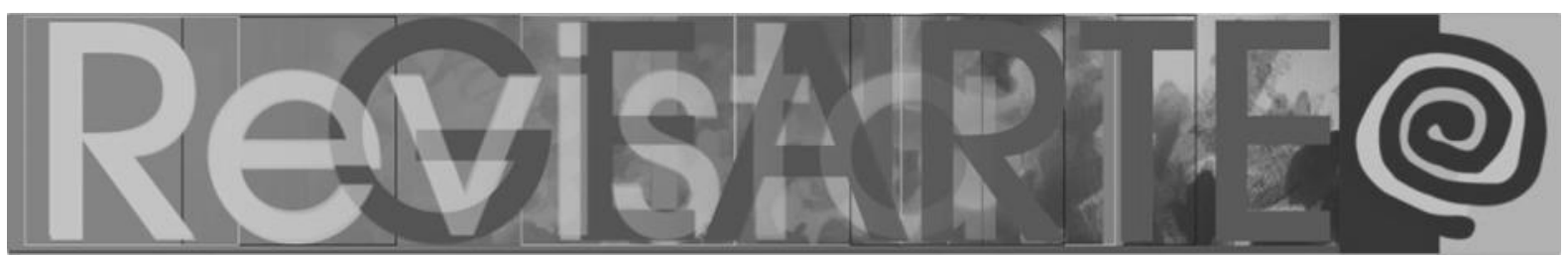

Desse modo, produzir-se-á uma sociedade majoritariamente dominada, explorada, artificial e espetaculista (consumista), oriunda da indústria da pobreza e da ignorância. Aí a necessidade humana se amplia com a produção da vida artificial, de uma vida inventada por necessidades fabricadas, em que a produção extranatural - "artificial" - é concebida e incorporada como natural. Assim, se constitui inversão de valores, em que aflora novo horizonte de necessidades humanas - as extranaturais, fundadas numa representação de valores produzidos.

Como resultado, passamos a ser a imagem que constituímos em nossa representação, eis o prenúncio tão óbvio - demarcado no tempo de outrora que, como espelho, a tecnocontemporaneidade viabiliza de modo potente na sociedade em rede, cuja edificação da alteridade é transmutada pelo valor da imagem envaidecida na valorização da Self, compreendida aqui como sociedade Self, cujos valores ontológicos são sobrepostos ao invólucro, ao rótulo, enfim, a imagem Self não é um registro qualquer, torna elemento edificante da inversão de valores, que edifica o pseudo Eu. E o desejo? O desejo próprio some como fumaça neste tipo de conjuntura social. Trata-se, pois, da introjeção do desejo alheio.

Assim, aos desprovidos de acúmulo de capital - aos pobres, não lhes é viabilizada a educação plena e por isto autogovernativa em prol do desenvolvimento da capacidade de reconhecer plenamente a cartografia de seu próprio desejo. Desejo próprio? É-lhe coibido: o desenvolvimento da vontade própria, da indocilidade criativa, da curiosidade crítica, pois os dirigentes da sociedade colonialista formam a massa social, para o desenvolvimento do pensamento padrão, uniforme, igualitário, perfeitamente servil, com serviços que Ihe devem ser impostos e restritos. Seres passivos. Acríticos. Vestem a imagem que lhe impõem, mas aplaudem para estas como se estas fossem verdadeiramente suas.

Instaura-se a estética da vida provinciana, colonialista dirigida pela ditadura da aparência. A apresentação vale como âmago da verdade - pseudo verdade, que se materializada pela imagem Self... O terrorismo provinciano colonizador, 


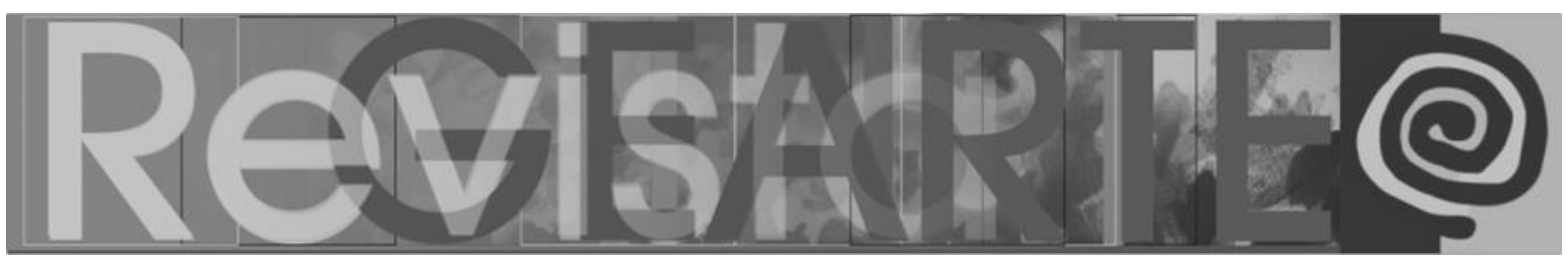

enquanto sombra permanente se fortalece pela ditadura de hábitos e costumes, que estão presentes nos impostos das taxas sociais que se paga e paga-se caro! Paga-se com a estética da vida servil, acrítica, com docilidade singular à obediência. Nesta forma social de vida, ser pobre torna-se pejorativo e por isto resulta no sofrimento de toda a crueldade preconceituosa, exploratória. Ainda de que modo ingênuo, acrítico, se torna necessário fingir-se ser o "outro". O "outro" melhor que si próprio. A consciência ingênua torna marcha da massa, que, como gado, ruma ao abatedouro.

Esta situação emblemática causa importante estrago histórico ao longo dos tempos do ontem, do hoje e certamente do amanhã se este paradigma não for revisitado corajosamente pela educação - capaz de prover intervenção sociocultural necessária, na concepção da educação brasileira descolonizadora e por isto libertária, em prol a moção à expressão digital crítica.

Para isto, se faz imperativo estancar a negligência de se repetir os mesmos erros em seus diferentes contextos históricos. A história apresenta pistas que podem indicar as fendas das quais necessitam ser revisitadas para (re)organizadas, corrigidas, estancadas. O desenvolvimento histórico - ético se faz pela intervenção tecnológica da humanidade sobre sua historicidade no tocante a sua situacionalidade. Cair sempre no mesmo buraco pode ser forte indicativo de uma sociedade frágil, vulnerável que ainda necessita compreender acerca da autoctonicidade em seu bem humanitário maior: a liberdade. A libertação de um povo. A capacidade autóctone de um povo tem que estar vinculada à sua capacidade autogovernativa, demarcada pela sua capacidade de expressão crítica.

\section{A negligência do desenvolvimento da expressão estético digital crítica}

O conhecimento por simulação acima apresentado, na década de 1990, instaura a transição da cognição perceptiva analógica para a uma nova forma de pensar, e assim de expressar. 


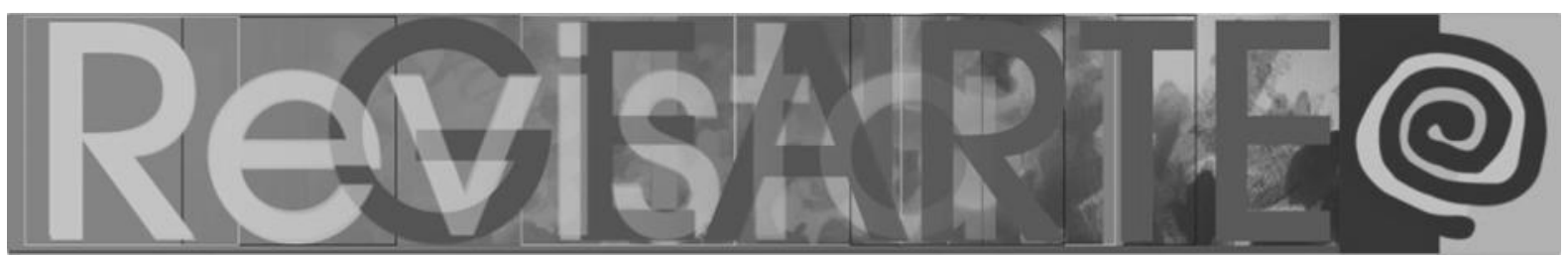

Neste contexto histórico, enquanto novas gerações nasciam, ainda que balbuciassem a tecnologia, em poucos anos - ou seja, em menos de uma década, já se encontrava o difícil cenário de se ensinar e se aprender, pois diante de educadores se posicionavam crianças/jovens imersos em suas expressões nato digitais, enquanto educadores e políticas educacionais negligenciavam o repertório juvenil em razão de excluírem a cultura digital juvenil dada a tecnofobia destes educadores bem como aos interesses políticos educacionais, promovendo importante preconceito e consequentemente rejeição ao arsenal sociocultural desta sociedade emergente, que nos anos subsequentes se somaria a comunidade global.

Neste paradigma, as políticas educacionais, quando muito, buscavam "capacitar" a performance destes educadores com frágeis cursos preparatórios de domínio computacional, muitas vezes, apenas para satisfazer algum uso nos laboratórios de informática, pois estes laboratórios eram a grande sensação - uma espécie de inovação educacional, que bastava pais, responsáveis e alunos visualizarem estes na escola, já se relacionava escola de "qualidade" e de "ponta". Esquecia-se de, e/ou não sabiam, avaliar junto aos educadores ali presentes, como estes equipamentos e magníficos laboratórios seriam utilizados na mediação do processo de ensino e aprendizagem.

É relevante lembrar que já se pronunciavam mídias sociais como ICQ, Orkut neste período, mas estas eram fortemente ignoradas pela quase totalidade dos educares no que tange à inserção das mesmas nos processos de ensino aprendizagem em prol do desenvolvimento da mente digital crítica. A relevância que se apresenta, pois, às mídias sociais, é que são ambientes digitais de relações humanas. São nas relações humanas que ações se tornam hábitos, hábitos se tornam costumes, costumes se ritualizam, ritos fazem parte dos gestos, símbolos, linguagem, comportamento de um povo e por assim dizer, da sua cultura.

Assim, da década de 1990 em diante, as políticas de uso dos laboratórios de informática educacionais são extremamente proibitivas ao ponto de muitos 


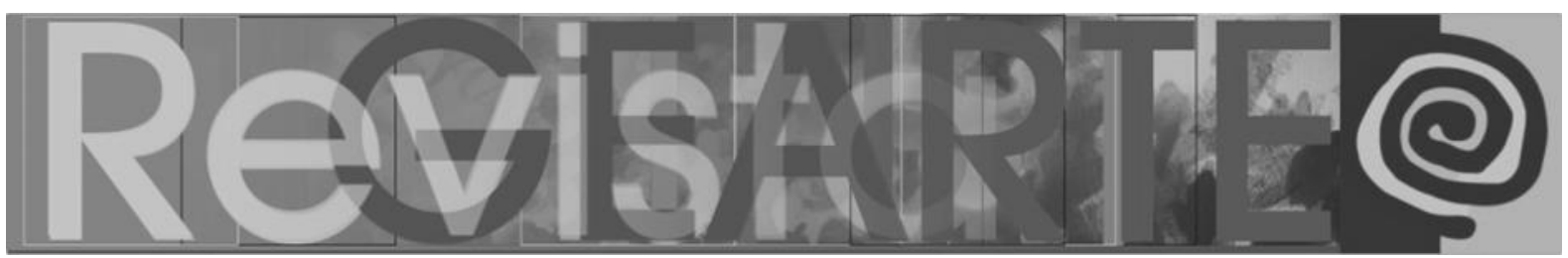

laboratórios "envelheceram" sem ou com quase nada de uso, por se tornarem tecnologias obsoletas aos novos que entraram. Ou ainda, outros como palcos educacionais centrados em ações pedagógicas pelo e-laissez-faire, ou seja, uma versão eletrônica do laissez-faire.

Ainda houve muitas empresas de desenvolvimento de softwares educativos que ganharam fortunas com o desenvolvimento de produtos sob o conhecimento por simulação em que transpunham o aprendizado convencional físico e/ou analógico, como da tabuada, de idiomas etc. no computador - não havia nada de novo no modus operandi de pensar, apenas o suporte que era digital. Ou seja, suporte digital para reforçar o pensamento analógico.

A questão crucial que se impõe ao exposto é que enquanto os professores se apresentavam tímidos em suas ações pedagógicas dada a tecnofobia, as políticas proibitivas e a atuação mercadológica de programas computacionais ganhavam cada vez mais espaço nas escolas, pois os computadores atraíam mais e mais alunos, uma vez que estes laboratórios se comportavam como verdadeiras vitrines para pais e responsáveis que matriculavam seus jovens nas escolas. Entretanto, o conhecimento por simulação atendia mais especificamente uma população que não era nato digital. Assim, o conhecimento por simulação transposto nestes aparatos não dialogava com o tempo cognitivo destes jovens, pois processos educativos se descontextualizavam da imersão de uma nova linguagem comunicacional, que já era realidade no universo juvenil.

Assim, gerações e gerações passam pela escola e saem despreparadas para o tecnouniverso digital em que se inserem, pois os processos educativos não privilegiaram o desenvolvimento da consciência digital crítica, culminando em pessoas sem autogovernabilidade, tornando-as refém da indústria cultural digital massiva em todos os segmentos da vida presente nas sociedades em rede. 


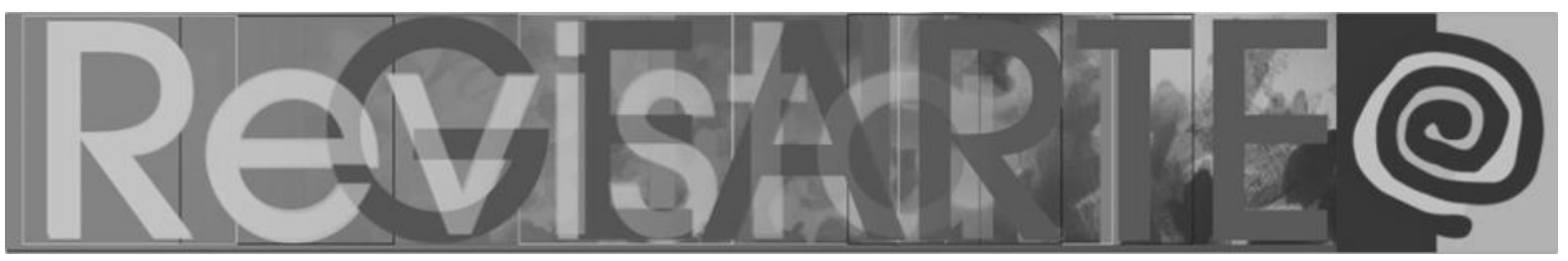

\section{\#SelfSociedadeEspetaculista?!}

O conhecimento por simulação da década de 1990 é sobreposto na contemporaneidade Ciber pelo acontecimento líquido, na contramão do "homem lento", personagem criada por Milton Santos (1994, 1996), e em direção ao paradigma da modernidade líquida do sociólogo Zygmunt Bauman (2000), cuja comunicação se caracteriza de modo contextualmente fluido (líquido), em que o sociólogo inglês John Urry (2005) adverte que o contexto não é apenas relevante, mas elemento estruturador de um sistema concomitantemente mutante, como diz Bohm: "A dança é que é fundamental, e não os dançarinos" (apud Urry, 2005, p. 238 , tradução nossa.)

O eixo determinante da sociedade em rede se identifica pela comunicação intercontextual. Manoel Castells (1999) conceitua um novo estado da mente humana que estabelece uma nova linguagem por Castells denominada de Metalinguagem, cuja natureza comunicacional se caracteriza pela interconexão entre som, imagem e texto, sendo o fim da separação e divisão entre as mídias audiovisuais e impressas e a oralidade, bem como o fim da separação entre cultura popular e erudita, entretenimento e informação.

A tecnocultura viabiliza, pois, a interação entre esses códigos comunicacionais num único universo digital interativo. Acede-se, assim, pela imersão comunicacional, um novo ambiente simbólico, o qual torna a virtualidade uma realidade expressiva que liga as manifestações em todos os seus tempos e espaços, contidas em nossa mente comunicativa, transformando a virtualidade em um sistema comunicacional e, portanto, real, como enaltece Castells (1999, p. 354):

Finalmente, talvez a característica mais importante da multimídia seja que ela capta em seu domínio a maioria das expressões culturais em toda a sua diversidade. Seu advento é equivalente ao fim da separação e até da distinção entre mídia audiovisual e mídia impressa, cultura popular e cultura erudita, entretenimento e informação, educação e persuasão. Todas as expressões culturais, da pior à melhor, da mais elitista à mais popular, vêm juntas nesse universo digital que liga, em um supertexto histórico gigantesco, as manifestações passadas, presentes e futuras da 


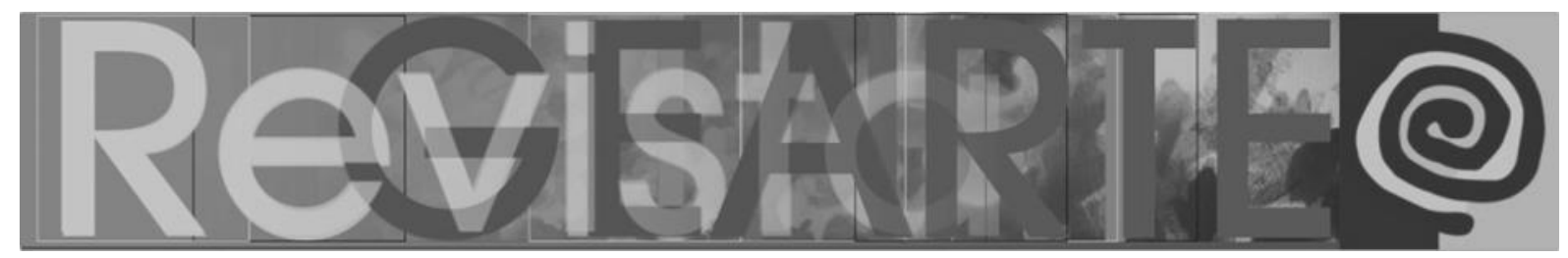

mente comunicativa. Com isso, elas constroem um novo ambiente simbólico. Fazem da virtualidade nossa realidade.

Ao se constituir este novo conceito de comunicação edifica-se a ascensão de sociedade em rede da humanidade. A realidade se vincula ao contexto como elemento epistemológico, passível da interpretação do signo digital, no contexto intrínseco da navegação. O contexto é elemento fundamental para determinar a rota de significados e valores que se constrói em uma caminhada virtualmente empírica nas cibervidas.

O ciberuniverso, pela sua natureza estrutural sistêmica e, portanto, complexa, é um sistema não linear, cuja fluidez líquida transcende e se contrapõe à concepção da verdade única, inquestionável de sistemas lineares presentes na física clássica.

A promoção da autonomia pela cultura digital se constitui, em outros termos, em uma rede de informações que, por meio de rotas escolhidas, poderá levar a pessoa a diferentes formulações. Para cada caminho traçado poderá haver resultados diferentes. Verdades que eram absolutas (e, de certo modo, universais) agora são relativizadas, de acordo com o contexto factual que vai se amalgamando no percurso, instituindo o contexto como elemento significante e significativo nesse meio: o contexto como elemento epistemológico do acontecimento, cujo acontecimento está intrínseco a consumação estética experienciada (DEWEY, 2000), num processo significativo de aprendizado pessoal.

A era Ciber mediada pela era Inter, em seus aspectos plurais se amalgamam com caráter democrático, horizontal, pela sua gênese no hipertexto, tem seu caráter expressivo e/ou apreciativo mediante a vivência de rotas navegadas, promovendo múltiplos caminhos capazes de cartografar diferentes e autônomas narrativas de acordo com rotas escolhidas se dinamizadas pela consciência crítica - autônoma - autogovernativa. Descobertas significativas necessitam de autonomias no/pelo percurso. Tais rotas, vale enaltecer, são propulsoras de acontecimentos contextuais, de processos de aprendizagem, cuja 


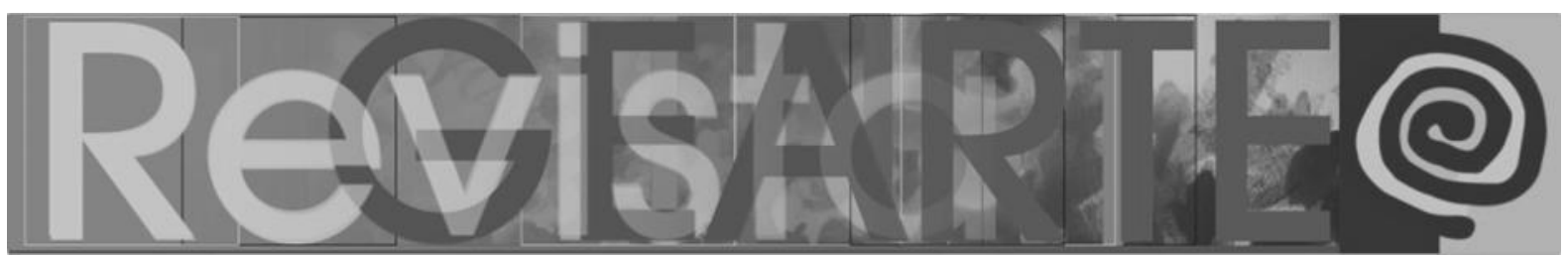

qualidade estética do aprendizado dependerá do nível de desenvolvimento da consciência: se ingênua, se intransitiva, se crítica, se fanática... Neste paradigma vincular-se-á a horizontalidade e/ou a verticalidade na internet em razão do nível de consciência.

Assim, o vértice central da qualidade estética da navegação e a consumação da rota vivenciada estão condicionados ao nível da capacidade cognitivo-perceptiva de cada pessoa, ou seja, ao nível de desenvolvimento da consciência. Paulo Freire (2005) no seu livro intitulado Educação como prática da liberdade assegura que somente a educação pode promover o desenvolvimento da consciência crítica. Criticidade é primordial para a autogovernabilidade e autonomia nas escolhas.

Caso contrário a consequência é a inversão de valores, da horizontalidade democrática da internet à verticalização do poder pelo tom da colonização com a imposição de valores, com a massificação pela coisificação do humano em sua artificialização através da introjeção dos valores alheios, pela mais profunda inversão de valores característicos de um povo acrítico, colonizado, à deriva à própria sorte. Vítimas da espetacularização, dada a introjeção de receitas alheias. Assim, se intoxicam com o que consomem como se suas fossem... O espetáculo da vida self, da imagem artificializada de si, que Ihe seria própria se de fato fosse sua... Vive-se a cópia ruim do original, que não the pertence e tão pouco o representa, a ilusão à realidade... vida fake?! Eis que se estabelece inversão de valores, do original para a cópia, da coisa para a imagem, da realidade para a aparência, como explica Feuerbach:

\footnotetext{
E sem dúvida o nosso tempo... prefere a imagem à coisa, a cópia ao original, a representação da realidade, a aparência ao ser... Ele considera que a ilusão é sagrada, e a verdade é profana. E mais: a seus olhos o sagrado aumenta à medida que a verdade decresce e a ilusão cresce, a tal ponto que, para ele, o cúmulo da ilusão fica sendo o cúmulo do sagrado (apud DEBORD, 1994, p. 13).
}

Assim, a vida indireta mediada pela representação e o seu espetáculo tornam-se instrumento indispensável para a materialização da sociedade 


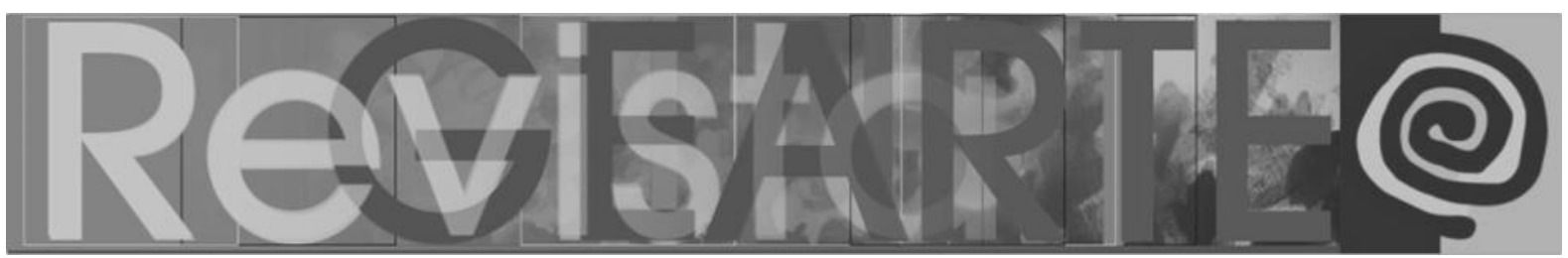

espetaculista, a qual está subordinada aos interesses econômicos da elite capitalista. Impõe-se uma cisão social entre explorador e o explorado, sob a égide de uma sociedade vertical, composta pelos que mandam e pelos que obedecem, sendo o consumo a própria sociedade, uma parte da sociedade e instrumento de unificação que faz, paradoxalmente, a comunicação oficial desta cisão social:

\begin{abstract}
O espetáculo apresenta-se ao mesmo tempo como a própria sociedade, como uma parte da sociedade e como instrumento de unificação. Como parte da sociedade, ele é expressamente o setor que concentra todo o olhar e toda a consciência. Pelo fato de esse setor estar separado, ele é o lugar do olhar iludido e da falsa consciência; a unificação que realiza é tão-somente a linguagem oficial da separação generalizada (DEBORD, 1994, p. 13).
\end{abstract}

Esse instrumento de domínio técnico-crítico restrito aos dirigentes é utilizado como forma de expressão impositiva dos valores que lhes são favoráveis, pois "a linguagem do espetáculo é constituída de sinais da produção" do resultado e projeto de uma sociedade curvada aos interesses de uma pequena minoria dominante (DEBORD, 1994, p. 14-5). Como afirma o autor:

\begin{abstract}
Considerado em sua totalidade, o espetáculo é ao mesmo tempo o resultado e o projeto do modo de produção existente. Não é um suplemento do mundo real, uma decoração que lhe é acrescentada. É o âmago do irrealismo da sociedade real. Sob todas as suas formas particulares - informação ou propaganda, publicidade ou consumo direto de divertimentos -, o espetáculo constitui modelo atual da vida dominante na sociedade. É a afirmação onipresente da escolha já feita na produção, e o consumo que decorre dessa escolha. Forma e conteúdo do espetáculo são, de modo idêntico, a justificativa total das condições e dos fins do sistema existente. $O$ espetáculo também é presença permanente dessa justificativa, como ocupação da maior parte do tempo vivido fora da produção moderna (DEBORD, 1994, pp. 14-5).
\end{abstract}

No sistema capitalista presente na sociedade em rede na contemporaneidade, o poder econômico controla, portanto, as relações de consumo através da consolidação da indústria ideológica massiva, a qual pode servir de instrumento para corroborar a formação unificada da subordinação, da aceitação, do consumo e da alienação da classe dominada (ditadura da moda).

A massa espetaculista dominada torna-se passiva, introjetando e consumindo acriticamente o produto espetaculoso, pois o "espetáculo que inverte 


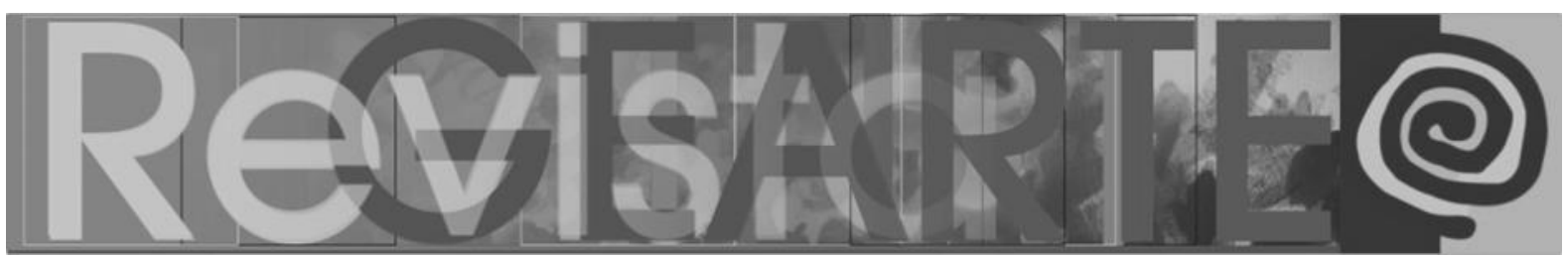

o real é efetivamente um produto" (DEBORD, 1994, p. 14-15). O produto se insere enquanto a própria vida. A escravidão da alma.

A técnica que é eficaz, eficiente e em geral espetacular é utilizada em prol do próprio interesse das classes dominantes, produzindo o resultado espetacular. A elite dominante o utiliza para o processo de consolidação da sociedade espetaculista. $\mathrm{O}$ espetáculo se caracteriza como o cerne da sociedade, a própria sociedade e instrumento de massificação.

A sociedade em rede dominada e massificada, que não possui liberdade de expressão e é restrita a ações automatizadas, torna-se objeto da elite aristocrática, ficando refém do espetáculo tecnicista, ou seja, escrava das ditaduras de produção e seu consumo pela via da própria expressão que não lhe é própria, acendendo assim o âmago de uma sociedade Fake.

\section{\#SociedadeFake?kkkkkkk}

"Só a verdade é que liberta/Chega de maldade e ilusão" (Renato Russo, em Perfeição)

Basta da promoção mercadológica pela ostentação sócio-econômicacultural, que maldosamente aprisiona, ilude em prol da vida fake! A sociedade em rede deve se alicerçar na horizontalidade pela rota da verdade líquida, balizando rotas autônomas de significado intercontextual, que segue na contramão da introjeção de valores pelo viés da ilusão.

O Brasil colonialista conduz historicamente a sociedade Fake: sociedade iludida, que vive a palidez do matiz da vida, cuja cor não Ihe é própria. Ter que ostentar o que efetivamente não lhe é próprio para inclusive buscar salvar-se de preconceito e sua consequente rejeição/marginalização à sua própria natureza. A introjeção de valores é um mecanismo de vida cruel, servil. O miserável embranquecimento da sociedade... O negro de cabelos lisos, loiros, com lente de contato para olhos azuis e/ou verdes, clareamento de pele, plásticas para 


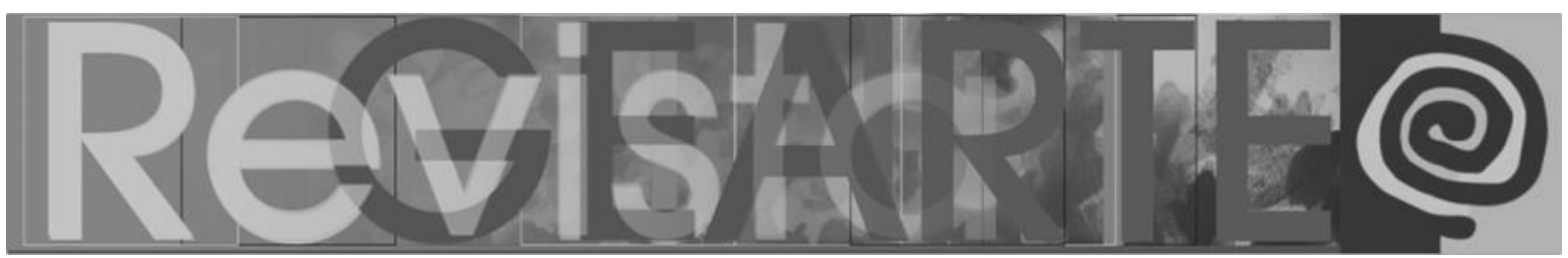

remodelar um nariz mais fino etc... A indústria do padrão de "beleza" — padrão da imagem... A imagem para inserção social.

As mudanças frenéticas de propagandas que persuadem a cada instante 0 novo padrão de beleza, como a forma de corpo ideal, por vezes mulheres com seio grandes, depois seios pequenos, homens exageradamente musculosos, barriga tanquinho... Andar pelas ruas é apreciar a vitrine da uniformização humana, à mercê da indústria da moda. Homens sem barba, agora com barbas gigantescas... O tempo do texto não cabe à infinidade histórica de situações em que a sociedade servil, colonizada introjeta a pseudo imagem ideal. Lembro-me quando fui ao salão de beleza há cerca de 30 anos atrás para fazer permanente em meu cabelo (um processo químico para deixar os cabelos crespos), pois sempre desejei ter cabelos crespos como de minhas duas irmãs. Tive que procurar outro salão, pois o que fui se negaram a "estragar" meus cabelos lisos...

Certamente daria um livro para registrar exemplos desta natureza....

Quer escravidão maior aos periféricos sociais?! Buscar consagrar de modo débil pseudo status para livramento de si próprio, de sua situacionalidade... Eis veneno, que é vendido como antídoto aos desprivilegiados. Pobres coitados pagam com seu próprio suor valores Selfies de vida Fake. A ilusão é produto introjetávelmente, vendido como adorno à edificação da Selfie para passaporte à pseudo liberdade. Conseguir viralizar estas Selfies torna-se prática do cotidiano para a busca da consagração da pseudo liberdade. Castelos de areia que se desmancham em água rasa para o surgimento da "nova moda" e assim se (re)fazem em novas Selfies. As selfies quando curtidas, e se viralizadas, se inserem como validação e consagração instantânea, fugaz da aceitabilidade social.

Ao que se vive hoje, na intensa e diria frenética imersão nas mídias sociais, é fato a naturalização das experiências vividas pseudo libertárias, em que não é mais possível desassociar a vida humana às vivências imergidas na virtualidade midiática do cotidiano presente. 


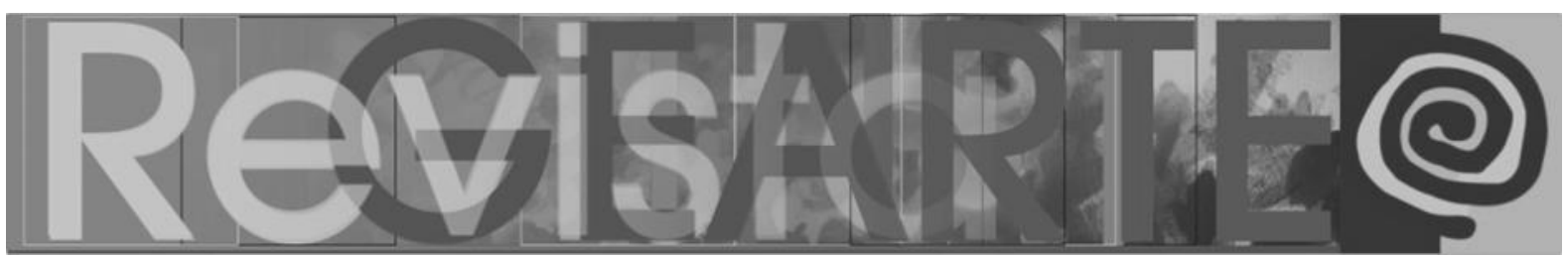

Vale relembrar que o Brasil, mesmo com fortes marcas de tanta desigualdade socioeconômica, há anos apresenta importantes marcadores que colocam a prática de vida dos brasileiros na internet, de modo recorrente, no topo do ranking mundial.

Observe que as fontes ${ }^{1}$ indicam que em 2004, a quantidade de usuários de Internet no Brasil era de aproximadamente 18 milhões (cerca de $8 \%$ da população brasileira), um número que representava a sétima posição no mundo. Em 2005, o internauta brasileiro foi quem mais usou Internet no mundo, isto é, em outubro do mesmo ano, o brasileiro que teve acesso à Internet em sua casa passou, em média, 18 horas e 42 minutos navegando - mais tempo do que americanos e japoneses, por exemplo.

O Yankee Group, Instituto de Pesquisa Americano, em um estudo chamado "A Second Wave: The Brazilian Internet User Forecast" projetou para o Brasil, em 2006, o número de 42,3 milhões de usuários de Internet. E ainda, neste mesmo ano, pelos cálculos do Ibope/NetRatings, 4,370 milhões de brasileiros ou $36,3 \%$ dos cerca de 12,036 milhões internautas domiciliares acessaram a Internet pela linha discada em janeiro desse ano.

Dos seis países (Estados Unidos, Canadá, Brasil, México, Argentina, Chile) com maior quantidade de usuários e microcomputadores nas Américas em 2003, o Brasil ocupava o terceiro lugar.

De acordo com pesquisa apresentada pela revista Exame em 26 de fevereiro de 2016, da organização We Are Social, José Borghi da Mullen Lowe antiga Borghi Lowe, o Brasil está em primeiro lugar no ranking mundial da população que mais passa tempo na internet e em segundo lugar em acesso às

Fonte: <http://www.ai.com.br/pessoal/indices/INTERNET.HTM>, acessado em 10 jun. 2008. 


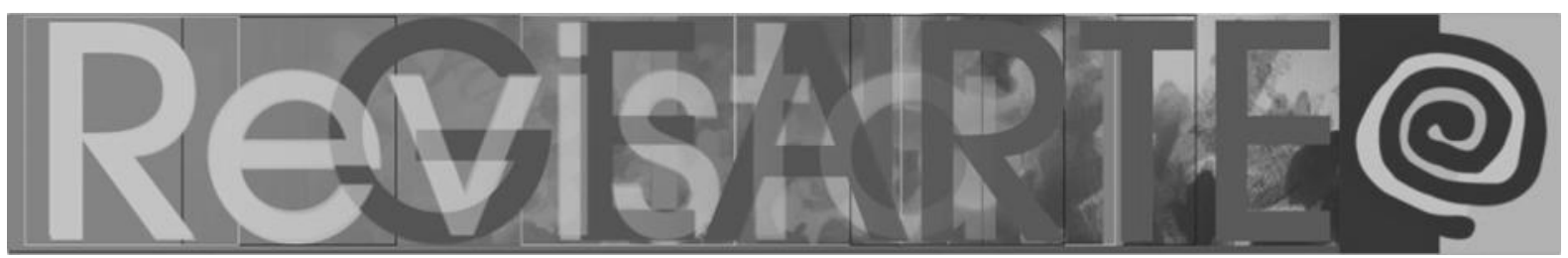

redes sociais. Em média, o brasileiro gasta cinco horas e 12 minutos por dia em computadores e três horas e 55 minutos em dispositivos móveis².

De acordo com os dados acima apresentados, o Brasil vem ocupando lugar de destaque no cenário internacional, concorrendo com importantes países que, em sua maioria, estão mais bem estruturados social, política e economicamente. A cibervida dos brasileiros e brasileiras estão no topo do ranking mundial.

Neste sentido, as políticas educacionais não podem segregar a cultura digital juvenil. Há a necessidade latente de se promover o desenvolvimento da mente digital crítica, agregando pedagogicamente o universo digital no tocante seja à expertise e/ou ao buraco que nossos alunos e alunas podem se encontrar, buscando promover ações educativas libertárias em prol do desenvolvimento da estética de suas ciberexpressões. A negligência histórica brasileira à educação crítica é um buraco no presente que não pode ser mantido como armadilha para as gerações futuras, pois:

\begin{abstract}
Uma educação libertadora deve dar conta da ascensão da ingenuidade à criticidade. Exatamente porque, significando tal ascensão uma inserção do homem na sua problemática e a sua capacidade de optar, as ameaças aos privilégios se fariam maiores, como maior a sua capacidade de rejeitar prescrições. Para o irracionalismo sectário surgia a humanização do homem como se fosse o seu contrário - a sua desumanização. Neste sentido, qualquer esforço para a humanização do homem pode ser compreendido como ação subversiva. A infração dos que se engajavam nesse esforço era a de crerem no homem, cuja destinação não é coisificar-se, mas humanizar-se (FREIRE, 2005).
\end{abstract}

Neste paradigma, se faz imperativo refletir sobre a qualidade estética das expressões digitais que acenam para a acriticidade, que podem conduzir a fragilização da capacidade de se atribuir valor sígnico em seu caráter pessoal na afetação à vida, dirimindo elaboração de ideias — de ideias autônomas, pois a uniformização da expressão gera a banalização dos sentidos.

2 Informação disponível em: <http://exame.abril.com.br/negocios/dino/pesquisa-coloca-brasil-notopo-de-ranking-de-acessos-online-mostra-jose-borghi-dino89089766131/>. Acesso em 28 fev. 2016. 


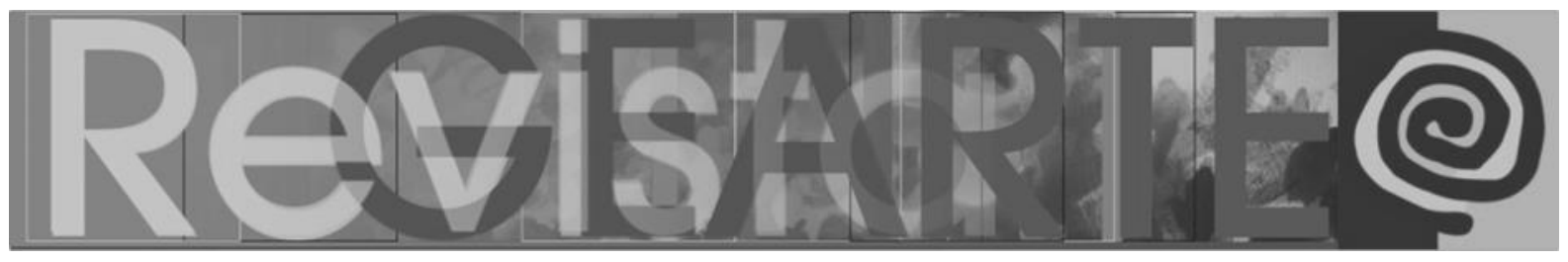

\section{A estética digital pela banalização dos sentidos}

Dada a característica das mídias sociais de intensificar a comunicação, a ausência do caráter autônomo da expressão oriunda da subjetividade pessoal pela carência dos sentidos no tocante ao seu exercício crítico/interpretativo culmina, por vezes, no abismo da banalização dos acontecimentos, subvertendo os valores intrínsecos da vida, negligenciando fatos e seus desdobramentos em razão da uniformização, que gera a perda da percepção do hipercontexto. O perigo da coisificação vai de encontro com a desumanização, que vai na contramão da educação libertadora.

Vale enaltecer que, a ideia enquanto produto mental e por assim dizer o constructo da imagem interna é inerente à expressão pessoal, sendo combustível da autogovernança. Entretanto, quando a imagem interna está sob a égide da introjeção da ideia alheia, em razão da acritidade dada a mente intransitiva, ingênua e/ou fanática, se pronunciam as práticas do domínio colonizador sobre o colonizado. $\mathrm{O}$ apoderamento da alma alheia, de seus desejos, que coisifica os sentidos com a introjeção da verdade única, padroniza e multiplica em escala nano, pela natureza fluida da modernidade líquida, disseminando ideias-prontas, aqui entendidas como ideias-produto.

Pertinente para este contexto a análise reflexiva de Gil Sevalho ao tratar pela perspectiva crítica a sociologia das ausências e emergências pelo prisma da epistemologia do Sul sob a pena de Boaventura de Souza Santos, em que propõe "uma prática científica politicamente comprometida com a justiça social, privilegiando o saber popular". (SEVALHO, 2012, p.7)

Neste paradigma, é imprescindível se ater ao contraponto de uma sociedade verticalizante, autoritária, que domina de modo cruel e vil em razão de seus interesses aristocráticos - elitistamente colonizador, pelo particular interesse capitalista de uma sociedade marginal, obediente, acrítica, com valores 


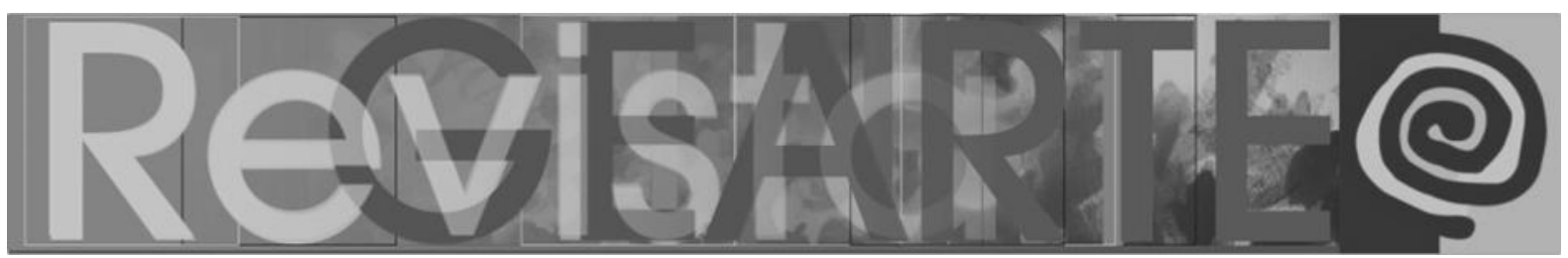

automatizados à prática consumista - espetaculista, cujo repertório da performance do consumo centra na máscara social pelos desejos introjetados.

Sevalho traz à cena o risco epidemiológico refletido pela aproximação do território do lugar a partir de Milton Santos "contrapondo-se a concretude do homem lento à artificialidade do discurso epidemiológico povoado pelo homem dos riscos", ao entender que:

\begin{abstract}
O homem lento resiste à fragmentação das identidades imposta pela globalização, tecendo criativamente a solidariedade no lugar; o homem dos riscos será o da velocidade, da modernidade, impondo uma ordem padronizadora, individualista e competitiva. (SEVALHO, 2012, p. 7)
\end{abstract}

A qualidade estética de nossas rotas de aproximação pela epidemiologia territorial que nos insere está, pois, vinculada a valores circunstanciais de oportunidade, cuja oportunidade saliente-se no vínculo da qualidade estética das conjunturas sócio-político-educacionais de um povo. Liberdade em seu ponto máximo à exaltação crítica humana emerge de seus processos conscientes pela construção paulatina e por isto efetiva de um povo. De um povo crítico. Um povo que não seja massa. Massa de manobra. Para não se restringir ao grito histérico, estéril, servil e mecânico, mas na expressão máxima do desejo consciente, autogovernativo, se faz imprescindível a educação estético-crítica.

Sempre me questiono sobre a mesmice epidemiológica de "kkkkkkkk" presente nas redes sociais, cujos "kkkks" são sempre tão uniformes que se evidencia a padronização da "graça" ... Neste cenário, como identificar "KaKaKadas" que engraçam alguma diferença estética entre si?

Se faz imperativo refletir sobre a qualidade estética das performances presentes nas mídias sociais, num processo contínuo de aprendizagem hipercontextual, buscando promover ciberintervenções arte/educativas, tendo como premissa a partilha com nossos alunos e alunas acerca das cibervivências, pela investigação dos vestígios estéticos, (re)visitando pegadas ciberexpressivas 


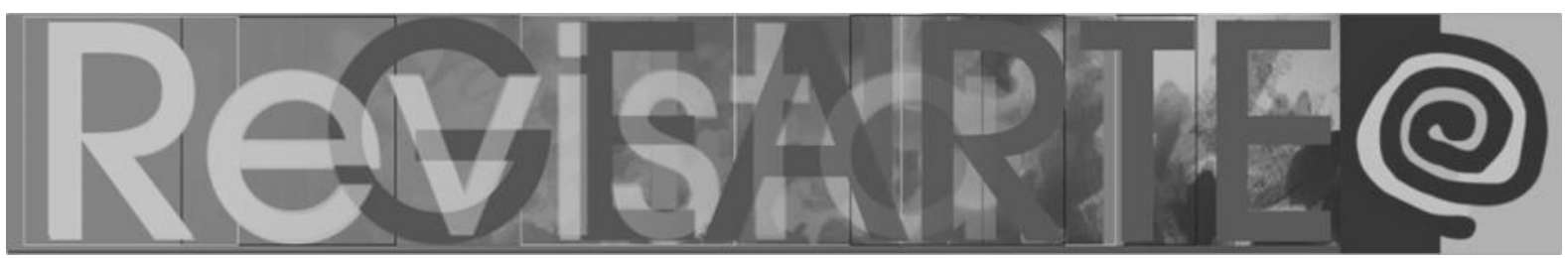

em busca da (re)significação das manifestações virais em prol do desenvolvimento da consciência crítica e identitária de nossos jovens.

\section{Finalizo com questões conclusivas ciberpedagógicas}

Como promover ações ciberarte/educativas críticas pela via da transmídia?

Chamo pela sua voz indagativa sobre a utilização dos emotions, gifs que têm sido produtos gráficos de intenso trânsito como forma de expressão nas mídias sociais. Qual o significado destes emotion e gifs no percurso da apropriação sígnica no contexto da expressão pessoal?

Ao se apropriar de tais símbolos, como podem ser (re)significados em prol da expressão crítica, autogovernativa nas mídias sociais?

Como você teceria pela educação ciberestética crítica a (re)significação de clichês e seus valores introjetados na contemporaneidade?

A segregação da cultura digital juvenil se instaura no âmago do que se carece aprender. Ao se encarar os buracos do presente, pelos vestígios das lacunas do passado, poder-se-á obter rotas mais seguras, para a promoção de pessoas mais criticamente vívidas, capazes de se autogovernem e, então, não serem vítimas das iscas do futuro, que podem, por vezes, estarem sendo tão bem preparadas no agora...

\section{Referências}

BARBOSA, Ana Mae T. Bastos. Arte/educação no Brasil. São Paulo: Perspectiva, 1999.

BAUMAN, Zygmunt. Modernidade líquida. Rio de Janeiro: Zahar, 2000.

BERNARDO, João. Estado. A silenciosa multidão do poder. São Paulo: Escrituras, 1998.

CASTELLS, M. A sociedade em rede. A era da informatização: Economia, sociedade e cultura. 2. ed. Vol. I. São Paulo: Ed. Paz e Terra, 1999.

DEBORD, Guy. A sociedade do espetáculo. Rio de Janeiro: Ed. Contraponto, 1994.

DEWEY, John. Arte como experiência. São Paulo: Martins Fontes, 2010.

FERRAZ, Maria Heloísa C. de T.; FUSARI, Maria F. de Rezende. Metodologia do ensino da arte. 2. Ed. São Paulo: Cortez, 2001. 


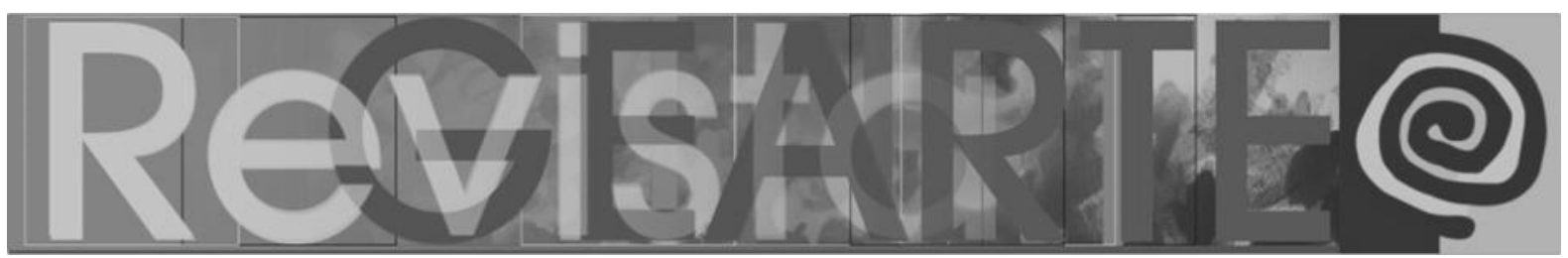

FREIRE, Paulo. Pedagogia da autonomia. Saberes necessários à prática educativa. 17. Ed. Rio de Janeiro: Paz e Terra, 2001.

FREIRE, Paulo. Educação como prática da liberdade. 28. ed. Rio de Janeiro: Paz e Terra, 2005.

LÈVY, Pierre. As tecnologias da inteligência. Rio de Janeiro: Ed. 34,1993.

LÈVY, Pierre. O que é virtual? Rio de Janeiro: Ed. 34, 1996.

LÈVY, Pierre. Cibercultura. São Paulo: Ed. 34, 1999.

MARX, Karl. O Capital. Crítica da economia política. Vol. I. Primeiro Livro. O processo de produção do capital. Tomo 2 (Capítulos XIII a XXV). São Paulo: Editor Victor Civita, 1984.

SEVALHO, Gil. O "homem dos riscos" e o "homem lento" e a teorização sobre o risco epidemiológico em tempos de globalização. Interface - Comunicação, saúde, educação. v.16, n. 40, p.7-19, jan./mar. 2012. Disponível em: <http://www.scielo.br/scielo.php?script=sci_art text\&pid=S1414-32832012000100002> Acesso em: 10 de setembro de 2019.

URRY, John. The complexities of the Global. Theory, culture \& society, London, Thousand Oaks and New Delhi, v. 22, n. 5, p. 235-254, 2005. DOI: 10.1177/0263276405057201

\section{Fernanda Pereira da Cunha}

Possui graduação em Educação Artística - Licenciatura Plena pela Fundação Armando Álvares Penteado, mestrado em Artes pela Universidade de São Paulo e doutorado em Artes pela Universidade de São Paulo. Atualmente é Professora Adjunta da Escola de Música e Artes Cênicas da Universidade Federal de Goiás (EMAC/UFG). Tem experiência na área de Artes, atuando principalmente nos temas: Intermídia, Cultura Digital, e-Arte/Educação. Foi vice coordenadora do Programa de Pós-Graduação Stricto Sensu (mestrado e doutorado) Interdisciplinar em Performances Culturais (EMAC/UFG) (2014-2016). É professora do Programa de Pós-Graduação Stricto Sensu (mestrado) em Música (EMAC/UFG). É coordenadora do Curso de Especialização em Arte/Educação Intermidiática (EMAC/UFG).

ORCID: https://orcid.org/0000-0001-7196-194X

E-mail: fernanda.pcunha@hotmail.com

Currículo: http://lattes.cnpq.br/8739909013018488

Recebido em 30 de setembro de 2019

Aceito em 22 de novembro de 2020 